\title{
ANALISIS KEKUATAN BENDING DAN KEKUATAN IMPACT KOMPOSIT EPOXY DIPERKUAT SERAT PELEPAH LONTAR
}

\author{
Melsiani Saduk ${ }^{1}$, Fransisko Piri Niron ${ }^{2}$ \\ ${ }^{1}$ Program Studi Teknik Mesin, Politeknik Negeri Kupang \\ 2Program Studi Mesin Perkakas, Politeknik Negeri Kupang \\ Jl. Adisucipto Po Box 139 Penfui Kupang \\ Telp. 0380-881246 \\ Email : melsianisd@gmail.com
}

\begin{abstract}
Natural fibers has been considered as reinforcement in composite materials which is environmentally friendly fiber instead of fiberglass. The use of natural fibers in the composite material is currently growing, along with the increasing use of such materials are widespread ranging from household appliances and industrial sector. The aims of this research was to determine the impact strength and bending strength of lontar fiber composite. The production method of this composite is hand lay up with random fiber orientation (random oriented fiber discontinuous). The composite were produced with a variety of fiber volume fraction of $10 \%$, $15 \%, 20 \%, 25 \%$ and $30 \%$. The bending strength of lontar fiber composite $140.235 \mathrm{MPa}$ and modulus of elasticity of $4440 \mathrm{Mpa}$ were obtained. The impact strength of lontar fiber composite and fiberglass were $0.439 \mathrm{~J} / \mathrm{mm}^{2}$ and $0.8333 \mathrm{~J} / \mathrm{mm}^{2}$ respectively.
\end{abstract}

Keywords: composite, lontar fiber, volume fraction, bending strength, impact strength

\section{PENDAHULUAN}

Adanya wacana rencana pelarangan penggunaan fiberglass saat ini menjadi salah satu pertimbangan untuk beralih pada penggunaan fiber yang ramah lingkungan. Fiberglass menggunakan serat kaca (matte) bisa menyebabkan gatal jika bersentuhan dengan kulit. Material ini terbuat dari bahan kimia dan serat kaca yang sukar terdegradasi secara alami. Pendaur ulangan fiberglass secara mekanik akan menghasilkan gas $\mathrm{CO}$ dan debu yang berbahaya untuk kesehatan sehingga dibutuhkan bahan baku alternatif yang lebih aman dan ramah lingkungan. Salah satu jenis serat alam yang yang dapat digunakan adalah serat lontar. Lontar (Borassus Flabellifer) adalah jenis palma yang bersifat serba guna yang populasinya banyak tersebar di Indonesia [1, 2].

Pada penelitian ini akan diambil serat dari pelepah lontar yang dapat menjadi alternatif bahan baku komposit. Komposit dengan penguat serat alam ini semakin intensif dikembangkan. Ini berkaitan dengan meluasnya penggunaan komposit pada berbagai bidang rekayasa dan industri serta tuntutan penggunaan material yang murah, ringan, sifat mekanik yang kuat dan tidak korosif, sehingga dapat menjadi bahan alternatif selain logam. Mulai dari yang sederhana seperti alat-alat rumah tangga sampai sektor industri baik industri skala kecil maupun industri skala besar seperti dalam industri pesawat terbang, otomotif, maupun untuk alat-alat olah raga $[3,4]$. Keuntungan mendasar yang dimiliki oleh serat alam adalah murah, mudah didapat dan juga sangat berlimpah. Dari segi ketersediaan bahan baku serat alam, di propinsi Nusa Tenggara Timur memiliki tanaman pohon lontar yang cukup melimpah. Perkiraan populasi pohon lontar di Indonesia, yaitu di Nusa Tenggara Timur sebanyak 4.407.000 pohon, Jawa Timur 5.000.000 pohon dan Sulawesi Selatan (hanya kabupaten Jeneponto) 300.000 pohon [5].

Di Nusa Tenggara Timur pohon lontar banyak dijumpai di pulau Sabu, Rote, Timor, Flores, pesisir timur dan pesisir selatan pulau Sumba dan di Jawa Timur. Populasi lontar paling banyak terdapat di sekitar pulau Madura, dan tumbuh pula di sekitar pantai utara pulau Jawa [2]. Dari populasi lontar yang ada di NTT, baru sekitar $25 \%$ yang disadap untuk kebutuhan konsumsi lokal maupun sebagai bahan baku industri rumah tangga. Karena itu salah satu usaha untuk 
meningkatkan kegunaan pohon lontar adalah memanfaatkan pelepah lontar sebagai bahan baku komposit yang dapat diaplikasikan pada berbagai industri [6].

Penelitian ini dititik beratkan untuk mengetahui kekuatan impact dan bending material sesuai dengan aplikasi yang diinginkan. Arah dan aplikasi dari penelitian ini adalah untuk mendapatkan material baru yang merupakan campuran epoxy dengan serat alam (serat pelepah lontar) sehingga diharapkan dapat bermanfaat sebagai alternatif untuk pembuatan body kapal ikan yang saat ini masih berbahan fiberglass

\section{METODOLOGI PENELITIAN}

Penelitian dilakukan pada komposit epoxy dengan menggunakan material serat alam pelepah lontar (Borassus Flabellifer). Sebelumnya serat diberi perlakuan, yaitu direndam dalam larutan Alkali $\mathrm{NaOH}$ sebanyak $5 \%$ per 1 liter aquades dengan waktu perendaman 3 jam guna memperbaiki sifat adhesif material. Spesimen dicetak dengan metode hand lay up. Hasil cetakan berupa spesimen uji dilakukan pengujian mekanik berupa uji impact dan bending $[7,8,9]$.

Pada penelitian ini perbandingan fraksi volume serat pelepah lontar terhadap resin epoxy divariasikan dengan perbandingan serat $10 \%, 15 \%$, 20\%, 25\% dan 30\%. Kekuatan impact dan kekuatan bending akan diuji dengan kondisi penambahan MEKPO sebesar $1 \%$ dan panjang serat lontar $\pm 2 \mathrm{~cm}$.

Desain spesimen uji komposit serat lontar dibuat berdasarkan standar ASTM D790 untuk pengujian bending dan standar ASTM D256 untuk pengujian impact seperti ditunjukkan pada Gambar 1 dan 2 berikut $[10,11]$.

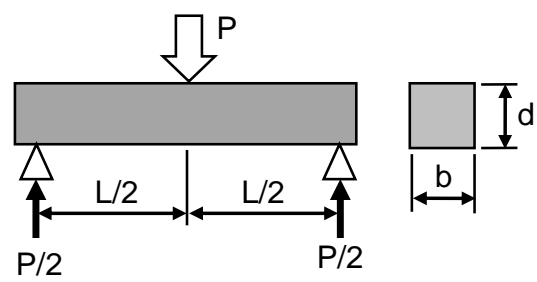

Gambar 1. Spesimen uji bending

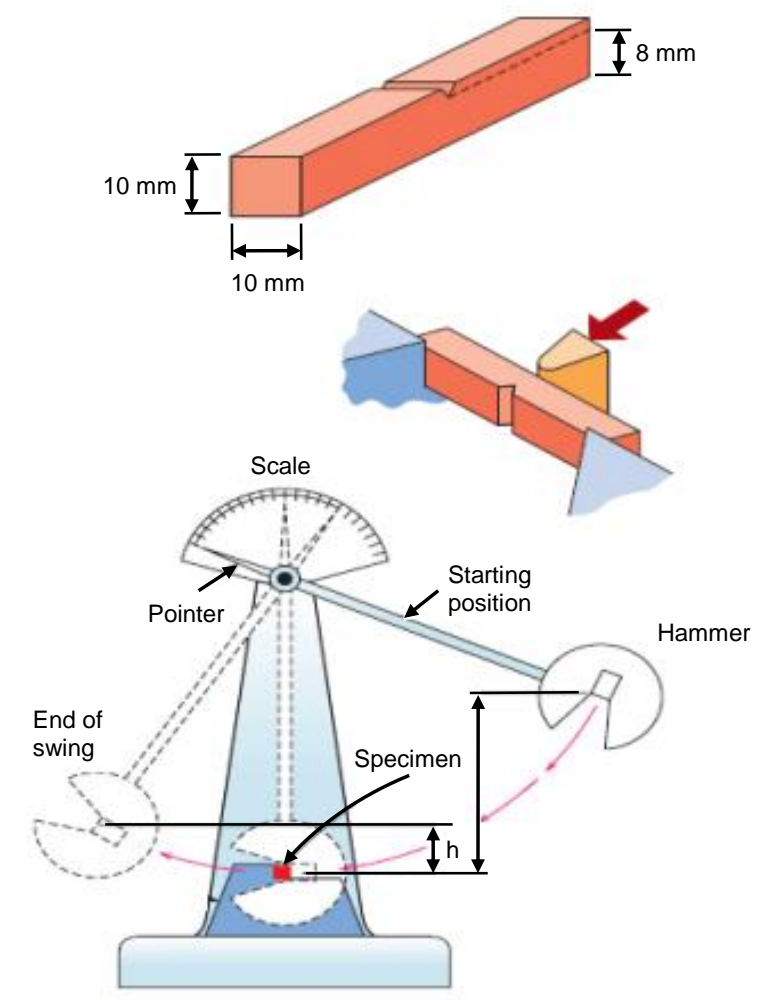

Gambar 2. Penampang uji impact

\section{HASIL DAN PEMBAHASAN}

Dari pengujian impact komposit epoxy berpenguat serat pelepah lontar didapatkan harga paling maksimal pada fraksi volume $30 \%$ yaitu sebesar $0,439 \mathrm{~J} / \mathrm{mm}^{2}$ sedangkan yang terendah berada pada fraksi volume $10 \%$ yaitu sebesar $0,134 \mathrm{~J} / \mathrm{mm}^{2}$. Hal ini menunjukkan bahwa semakin bertambahnya jumlah serat pada komposit maka harga impact menjadi semakin besar. Sedangkan energi serap yang paling tinggi juga terdapat pada fraksi volume $30 \%$ yaitu sebesar $1,28 \mathrm{~J}$, dan energi serap yang terkecil yaitu $0,12 \mathrm{~J}$ berada pada fraksi volume $10 \%$. Hal ini juga sama menunjukkan bahwa semakin besar jumlah serat yang terkandung pada komposit epoxy, maka semakin besar energi yang diserap oleh komposit seperti ditampilkan pada Tabel 1. 
Tabel 1 Data pengujian kekuatan impact

\begin{tabular}{|c|c|c|c|c|c|c|}
\hline Fraksi Volume & $\begin{array}{c}\text { No } \\
\text { Spesimen }\end{array}$ & $\begin{array}{l}\text { Tebal } \\
(\mathrm{mm})\end{array}$ & $\begin{array}{l}\text { Lebar } \\
(\mathrm{mm})\end{array}$ & $\begin{array}{l}\text { Luas Penampang } \\
\text { dibawah takik } \\
\left(\mathrm{mm}^{2}\right)\end{array}$ & $\begin{array}{l}\text { Energi } \\
\text { Serap } \\
\text { (J) }\end{array}$ & $\begin{array}{l}\text { Harga } \\
\text { Impact } \\
\left(\mathrm{J} / \mathrm{mm}^{2}\right)\end{array}$ \\
\hline \multirow{7}{*}{ Fraksi Volume $10 \%$} & 1 & 0.6 & 1.4 & 0.84 & 0.1 & 0.119 \\
\hline & 2 & 0.5 & 1.6 & 0.8 & 0.1 & 0.125 \\
\hline & 3 & 0.6 & 1 & 0.96 & 0.15 & 0.156 \\
\hline & 4 & 0.5 & 61.45 & 0.725 & 0.1 & 0.138 \\
\hline & 5 & 0.64 & 1.5 & 0.96 & 0.15 & 0.156 \\
\hline & 6 & 0.65 & 1.4 & 0.91 & 0.1 & 0.1099 \\
\hline & Rata-Rata & 0.582 & 11.392 & 0.866 & 0.117 & 0.134 \\
\hline \multirow{7}{*}{ Fraksi Volume 15\% } & 1 & 0.45 & 1.46 & 0.657 & 0.125 & 0.19 \\
\hline & 2 & 0.5 & 1.4 & 0.7 & 0.125 & 0.178 \\
\hline & 3 & 0.54 & 1.4 & 0.756 & 0.12 & 0.158 \\
\hline & 4 & 0.54 & 1.6 & 0.864 & 0.12 & 0.139 \\
\hline & 5 & 0.4 & 1.45 & 0.58 & 0.125 & 0.216 \\
\hline & 6 & 0.5 & 1.46 & 0.73 & 0.125 & 0.171 \\
\hline & Rata-Rata & 0.488 & 1.462 & 0.715 & 0.123 & 0.175 \\
\hline \multirow{7}{*}{ Fraksi Volume $20 \%$} & 1 & 0.48 & 1.4 & 0.672 & 0.225 & 0.335 \\
\hline & 2 & 0.5 & 1.4 & 0.7 & 0.225 & 0.321 \\
\hline & 3 & 0.4 & 1.46 & 0.584 & 0.225 & 0.385 \\
\hline & 4 & 0.45 & 1.46 & 0.657 & 0.23 & 0.35 \\
\hline & 5 & 0.48 & 1.46 & 0.7008 & 0.225 & 0.321 \\
\hline & 6 & 0.5 & 1.46 & 0.72 & 0.225 & 0.308 \\
\hline & Rata-Rata & 0.468 & 1.440 & 0.672 & 0.226 & 0.337 \\
\hline \multirow{7}{*}{ Fraksi Volume $25 \%$} & 1 & 0.5 & 1.46 & 0.73 & 0.25 & 0.342 \\
\hline & 2 & 0.5 & 1.46 & 0.73 & 0.25 & 0.342 \\
\hline & 3 & 0.46 & 1.4 & 0.644 & 0.25 & 0.388 \\
\hline & 4 & 0.4 & 1.5 & 0.6 & 0.25 & 0.417 \\
\hline & 5 & 0.4 & 1.4 & 0.56 & 0.25 & 0.446 \\
\hline & 6 & 0.5 & 1.5 & 0.75 & 0.25 & 0.333 \\
\hline & Rata-Rata & 0.460 & 1.453 & 0.669 & 0.250 & 0.378 \\
\hline \multirow{7}{*}{ Fraksi Volume $30 \%$} & 1 & 0.5 & 1.4 & 0.7 & 0.3 & 0.428 \\
\hline & 2 & 0.5 & 1.4 & 0.7 & 0.3 & 0.428 \\
\hline & 3 & 0.45 & 1.46 & 0.657 & 0.3 & 0.457 \\
\hline & 4 & 0.48 & 1.5 & 0.72 & 0.3 & 0.417 \\
\hline & 5 & 0.5 & 1.4 & 0.7 & 0.3 & 0.428 \\
\hline & 6 & 0.45 & 1.4 & 0.63 & 0.3 & 0.476 \\
\hline & Rata-Rata & 0.480 & 1.427 & 0.685 & 0.300 & 0.439 \\
\hline
\end{tabular}


Untuk tabel nilai rata-rata energi serap dan yang terjadi pada sepesimen uji bending harga impact dari komposit serat epoxy adalah mekanisme patahan pull out, dimana berpenguat serat pelepah lontar dapat dilihat pada ujung patahan spesimen patahan pada Tabel 2 di bawah ini.

Tabel 2 Nilai rata-rata E serap dan harga impact komposit epoxy

\begin{tabular}{|c|c|c|c|}
\hline No & $\begin{array}{c}\text { Fraksi } \\
\text { Volume } \\
(\%)\end{array}$ & $\begin{array}{c}\text { E Serap } \\
(\mathrm{J})\end{array}$ & $\begin{array}{c}\text { Harga } \\
\text { Impact } \\
(\mathrm{J} / \mathrm{mm} 2)\end{array}$ \\
\hline 1 & 10 & 0.117 & 0.134 \\
\hline 2 & 15 & 0.123 & 0.174 \\
\hline 3 & 20 & 0.506 & 0.337 \\
\hline 4 & 25 & 0.84 & 0.378 \\
\hline 5 & 30 & 1.28 & 0.439 \\
\hline
\end{tabular}

Hubungan antara fraksi volume dengan energi serap disajikan pada Gambar $3 a$ dan hubungan antara fraksi volume dengan harga impact ditampilkan pada Gambar 3b.

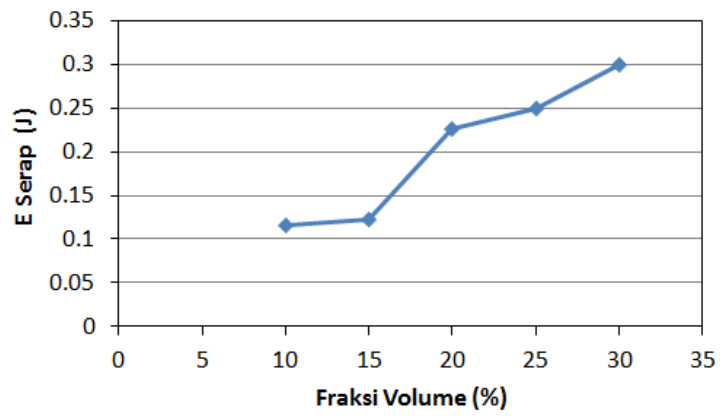

Gambar 3a Grafik hubungan fraksi volume dengan energi

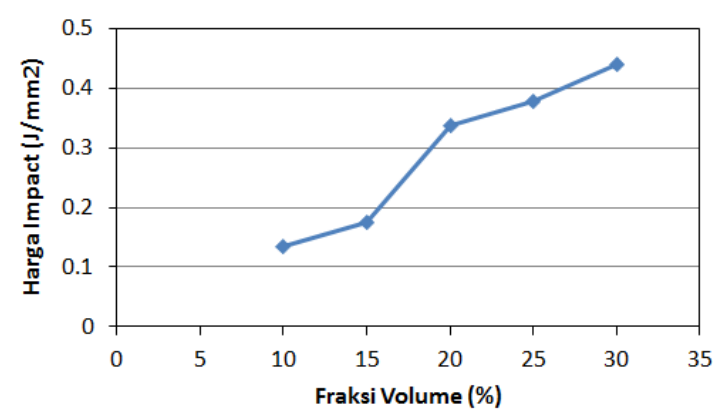

Gambar 3b Grafik hubungan fraksi volume dengan harga impact spesimen muncul ujung patahan serat seperti ditunjukkan pada Gambar 4.

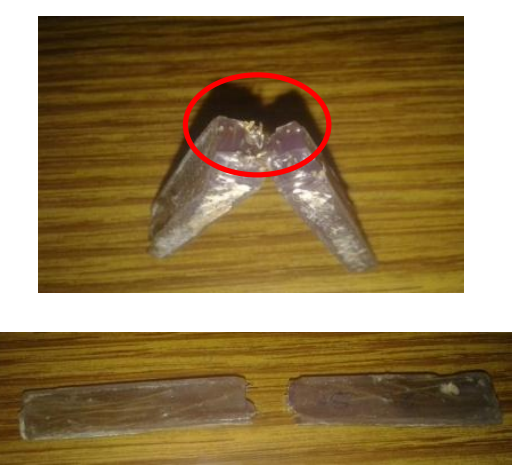

Gambar 4 Penampang patahan uji impact

Mekanisme pull out terjadi ketika ikatan antara resin epoxy mengalami kegagalan, karena beban kejut yang diberikan maka serat tidak dapat menanggung beban, sehingga proses terjadinya patahan berlangsung secara bersamaan. Untuk pengujian impact kapal fiberglass, maka data pengujian impact dapat dilihat pada Tabel 3.

Dari hasil yang didapatkan dalam penelitian tahap pertama, nilai kekuatan bending dan impact serat pelepah lontar masih belum dapat digunakan sebagai bahan utama pembuatan body kapal ikan. Nilai kekuatan impact kapal fiberglass sebesar $0,8333 \mathrm{~J} / \mathrm{mm}^{2}$, jauh lebih besar dari nilai kekuatan impact serat lontar yaitu sebesar 0,4391 $\mathrm{J} / \mathrm{mm}^{2}$. Setelah dilakukan penelitian dan hasil wawancara dengan pihak industri pembuatan kapal, ternyata hal ini disebabkan adanya bahan berupa talc (tepung khusus) yang harusnya digunakan saat mencampur katalis, resin dan hardener. Bahan talc inilah yang meningkatkan keuletan dan kelenturan komposit. Dengan demikian pada penelitian berikutnya akan digunakan bahan tambahan berupa talc kemudian diuji kekuatan impact dan bendingnya dan dilanjutkan dengan pembuatan prototype body kapal ikan.

Pengujian spesimen uji impact juga menunjukkan bahwa pada komposit epoxy dengan serat pelepah lontar sebagai penguat menunjukkan bahwa mekanisme patahan 
Tabel 3 Data kekuatan impact kapal fiberglass

\begin{tabular}{|c|c|c|c|c|c|}
\hline No Spesimen & $\begin{array}{c}\text { Tebal } \\
(\mathrm{mm})\end{array}$ & $\begin{array}{c}\text { Lebar } \\
(\mathrm{mm})\end{array}$ & $\begin{array}{c}\text { Luas Penampang } \\
\text { dibawah takik } \\
(\mathrm{mm} 2)\end{array}$ & $\begin{array}{c}\text { Energi } \\
\text { Serap } \\
(\mathrm{J})\end{array}$ & $\begin{array}{c}\text { Harga } \\
\text { Impact } \\
(\mathrm{J} / \mathrm{mm} 2)\end{array}$ \\
\hline 1 & 0,6 & 1,4 & 0,84 & 0,7 & 0,833 \\
\hline 2 & 0,6 & 1,4 & 0,84 & 0,7 & 0,833 \\
\hline 3 & 0,6 & 1,4 & 0,84 & 0,7 & 0,833 \\
\hline Rata-Rata & 0,6 & 1,4 & 0,84 & 0,7 & 0,833 \\
\hline
\end{tabular}

\section{Pengujian Bending}

Pengujian bending dilakukan pada komposit yang dibuat dengan serat pelepah lontar yang telah mengalami perlakuan 5\% $\mathrm{NaOH}$ selama 180 menit, dimana serat pelepah lontar mempunyai kekuatan yang optimal. Pengujian ini dilakukan untuk mengetahui apakah ada perubahan sifat mekanis terhadap kekuatan bending dengan variasi fraksi volume yang berbeda antara $10 \%, 15 \%, 20 \%$, 25\% dan 30\% serat. Dengan demikian data hasil pengujian bending komposit polyester dengan serat pelepah lontar sebagai penguat berupa kekuatan bending dan modulus elastisitas dapat dilihat pada Tabel 4 di bawah ini.

Tabel 4. Data pengujian kekuatan bending

\begin{tabular}{|c|l|l|l|}
\hline No. & $\begin{array}{c}\text { Fraksi } \\
\text { Volume } \\
(\%)\end{array}$ & $\begin{array}{c}\text { Fmax }_{\operatorname{maxg}} \text { avg } \\
(\mathrm{kgf})\end{array}$ & $\begin{array}{c}\text { Tegangan } \\
\text { Bending } \\
\text { avg }\end{array}$ \\
\hline 1 & 10 & 15.3 & 11.29 \\
\hline 2 & 15 & 15.64 & 11.55 \\
\hline 3 & 20 & 16.995 & 12.55 \\
\hline 4 & 25 & 17.33 & 12.8 \\
\hline 5 & 30 & 19.37 & 14.3 \\
\hline
\end{tabular}

Pada Gambar 5 terlihat bahwa grafik tegangan bending mengalami kenaikkan tegangan dikarenakan adanya penambahan serat. Grafik tersebut menjelaskan semakin tinggi fraksi volume serat maka tegangan bendingnya semakin tinggi. Hal ini ditunjukkan pada fraksi volume $10 \%$ besarnya tegangan bending yaitu $11,29 \mathrm{kgf} / \mathrm{mm}^{2}$ lebih kecil dibanding fraksi volume $30 \%$ yang sebesar $14,30 \mathrm{kgf} / \mathrm{mm}^{2}$. Dari hasil diatas menunjukkan bila serat semakin banyak serat maka tegangan bendingnya semakin besar.
Besarnya regangan yang terjadi juga bersesuaian dengan besarnya tegangan seperti tampak pada Gambar 6. Hal ini menunjukkan bahwa kelima variasi fraksi volume serat mempunyai karakteristik yang hampir sama.

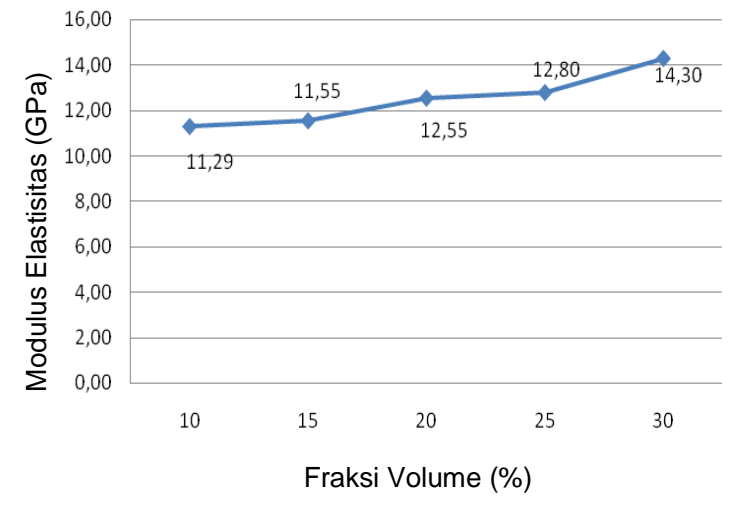

Gambar 5. Grafik hubungan fraksi volume dengan tegangan bending

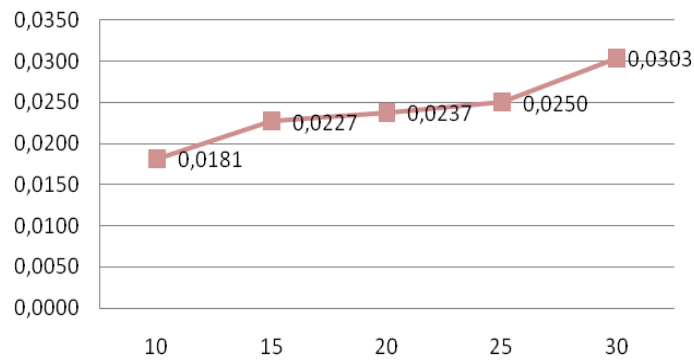

Gambar 6. Grafik hubungan fraksi volume dengan regangan bending 


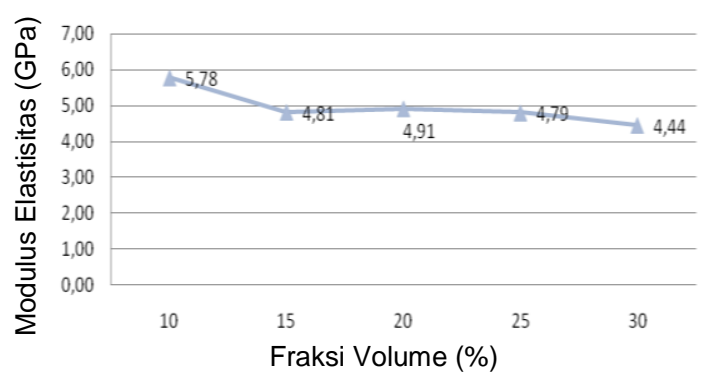

Gambar 7 Grafik hubungan fraksi volume dengan modulus elastisitas

Gambar 6 menunjukkan besarnya nilai modulus elastisitas komposit serat pelepah lontar dan resin epoxy dengan variasi fraksi volume $10 \%$ sampai $30 \%$. Dari grafik hubungan antara modulus elastisitas serat pelepah lontar dan resin epoxy diatas, dapat diketahui bahwa pada komposit tersebut dengan fraksi volume $10 \%$ yaitu 5,78 Gpa mengalami penurunan yang sampai fraksi volume 30\% yaitu sebesar 4,44 Gpa. Dari grafik diketahui bahwa modulus elastisitas mengalami penurunan yang sangat signifikan karena volume serat bertambah banyak sedangkan volume resin berkurang.

Dengan jumlah volume serat yang banyak serta kondisi serat yang kaku akibat perlakuan alkali menyebabkan serat sulit untuk diatur atau diluruskan saat diletakan pada cetakan. Kondisi serat yang tidak lurus mempengaruhi aliran matriks ke serat yang tidak terdistribusi secara sempurna, bahkan terjadi penumpukan serat (serat tidak teratur dengan rapi) sehingga pada saat diberikan beban bending walaupun tegangannya meningkat, tetapi modulus elastisitasnya mengalami penurunan.

Pengujian spesimen uji bending juga menunjukkan bahwa pada komposit epoxy dengan serat pelepah lontar sebagai penguat menunjukkan bahwa mekanisme patahan yang terjadi pada sepesimen uji bending adalah mekanisme patahan pull out, dimana pada ujung patahan spesimen patahan spesimen muncul ujung patahan serat seperti ditunjukkan pada Gambar 8.

Mekanisme pull out terjadi ketika ikatan antara resin epoxy dan serat melemah ketika beban yang diberikan bertambah. Pada saat resin polyester mengalami kegagalan, serat masih dapat menanggung beban, sehingga proses terjadinya patahan tidak berlangsung secara bersamaan $[12,13]$.
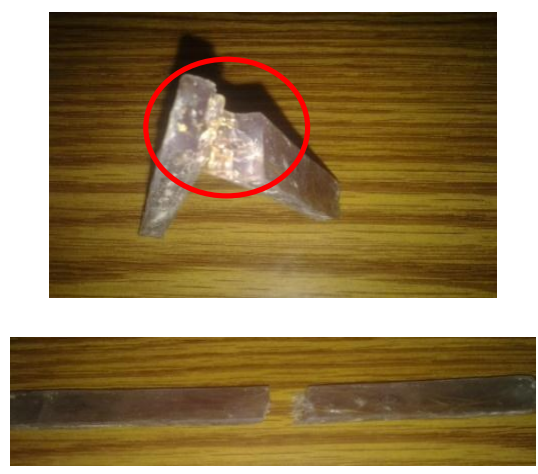

Gambar 8. Penampang patahan uji bending

\section{KESIMPULAN}

1. Pengaruh variasi fraksi volume terhadap perubahan sifat mekanis (kekuatan impact dan kekuatan bending) dari komposit dengan digunakannya serat pelepah lontar sebagai penguat

2. Pengujian spesimen uji impact dan uji bending menunjukkan bahwa pada komposit epoxy dengan serat pelepah lontar sebagai penguat menunjukkan bahwa mekanisme patahan yang terjadi pada sepesimen uji bending adalah mekanisme patahan pull out

3. Nilai kekuatan bending pada komposit serat lontar sebesar $14,30 \mathrm{kgf} / \mathrm{mm}^{2}$ atau $140,235095 \mathrm{MPa}$. Sedangkan nilai kekuatan impact yang dihasilkan sebesar $0,439 \mathrm{~J} / \mathrm{mm}^{2}$ dengan energi serap sebesar $1,28 \mathrm{~J}$.

\section{DAFTAR PUSTAKA}

[1] Badan penelitian dan pengembangan kehutanan kementrian kehutanan, 2010. Lontar (Borassus Flabellifer) sebagai sumber energi bioetanol potensial

[2] Lutony, T.L. 1993. Tanaman Sumber Pemanis. P.T.Penebar Swadaya, Jakarta.

[3] Imra, Iswandi. (2009). Pengaruh Proses Vakum dan Variasi Tekanannya terhadap Sifat Tarik Komposit Serat Alam. Tugas Akhir, Jurusan Teknik Mesin, Universitas Andalas, Padang. 
[4] Budinski K.G. 1995. Engineering Material Properties and Selection, 4th, Prentice Hall,Inc A Simon and Schuster Company, USA.

[5] Mahmud, Z., D. Allorerung dan Amrizal, 1991. Prospek tanaman kelapa, aren, lontar dangewang, untuk menghasilkan gula. Buletin Balitka No. 14. Balai Penelitian Kelapa. Manado.

[6] Joseph, G.H.M.M, M. Rumokoi dan Z. Mahmud. 1990. Perbaikan teknik penyadapan nira lontar di Nusa Tenggara Timur. Buletin Balitka No. 11. Balai Penelitian Kelapa. Manado.

[7] Callister, W. D. 1991. Material Science and Engineering an Introduction, John Willey and Sons Inc, New York.

[8] Diharjo,K. 2008. Pengaruh Perlakuan Alkali terhadap Sifat Tarik Bahan Komposit Serat Rami-Polyester. Jurusan Teknik Mesin, Fakultas Teknologi Industri, Universitas Kristen Petra.

[9] Jacobs, J.A. Kilduft T.K. 1994. Engineering Material Technology Structure, Processing, Property and Selection 2. Prentice Hall,Inc A Simon Schuster Company, USA.
[10] ASTM D790 - 15e2. Standard Test Methods for Flexural Properties of Unreinforced and Reinforced Plastics and Electrical Insulating Materials.

[11] ASTM D256 - 10e1. Standard Test Methods for Determining the Izod Pendulum Impact Resistance of Plastics.

[12] Reddy K.O, Maheswari C.U, Rajulu, A.V and Guduri, B.R. 2009. Thermal Degradation Parameters and Tensile Properties of Borassus flabellifer Fruit Fiber Reinforcement. Journal of Reinforced Platics and Composites.

[13] Venkatesha g. Prasanna and venkata k. Subbaiah. 2011. Chemical resistance and compressive properties of bananapalmyra fibers reinforced epoxyunsaturated polyster blended composites. Abstarcts International J.of Multidispl.Research \& Advcs. in Engg.(IJMRAE), Vol. 3, No. II, pp. 123130 